\title{
Oocyte and somatic tyrosine tRNA genes in Xenopus laevis
}

\author{
Françoise Stutz, Evelyne Gouilloud, and Stuart G. Clarkson \\ Department of Microbiology, Centre Médical Universitaire, 1211 Geneva 4, Switzerland
}

\begin{abstract}
Over a period of many months, Xenopus oocytes stockpile large quantities of tRNA for use during the first few hours of embryogenesis. To test the idea that these tRNAs are transcribed from one set of genes and that another set is used by somatic cells, we used synthetic oligonucleotides to analyze the sequence and steadystate levels of unspliced tyrosine tRNA precursors in Xenopus laevis oocytes, embryos, and cultured kidney cells. These analyses identify four kinds of tyrosine tRNA genes, two oocyte-type and two somatic-type, whose unspliced transcripts are distinguishable from one another by their different $5^{\prime}$ leader and intervening sequences. The oocyte-type tyrosine tRNA precursors are present in oocytes, very abundant in gastrula embryos, but absent from postembryonic somatic cells. The somatic-type precursors are undetectable in oocytes but are found in gastrula and later stage embryos and in somatic cells. The major switch from oocytetype to somatic-type transcripts occurs early during embryogenesis, between the midblastula transition and the onset of neurulation, but some oocyte-type precursors are also detectable in tadpoles.
\end{abstract}

[Key Words: tRNA gene; tRNA precursors; intervening sequences; developmental regulation; embryogenesis; Xenopus laevis]

Received March 17, 1989; accepted May 19, 1989.

Xenopus laevis contains an unusually large number of tRNA genes $(\sim 8000$ per haploid genome; Clarkson et al. 1973), many of which are located in extensive multigene families (Müller and Clarkson 1980; Rosenthal and Doering 1983). One such family is composed of $3.18-\mathrm{kb}$ DNA fragments, each of which contains eight genes for seven different tRNA species, that are repeated tandemly $\sim 150$ times at a single chromosomal locus (Fostel et al. 1984; Müller et al. 1987).

A potential explanation for these highly repeated genes is that they are needed to satisfy the unusual synthetic demands of oogenesis, during which single oocytes accumulate $\sim 90 \mathrm{ng}$ of tRNA (Dixon and Ford 1982). The tRNA requirements of somatic cells could be met by a smaller number of genes located in a different sequence context. A precedent for this type of developmental regulation is provided by the Xenopus oocytetype and somatic-type 5S RNA genes (for review, see Wolffe and Brown 1988).

One of the eight genes on the 3.18 -kb repeat contains an intervening sequence; it codes for tyrosine tRNA and is referred to as TyrC. A second kind of tRNA ${ }^{\mathrm{Tyr}}$ gene has been isolated from $X$. laevis that is present in 1-3 copies per haploid genome; this gene, referred to as TyrD, differs from TyrC by a single purine transition in the coding region, by extensive differences in the intervening sequence and flanking regions, and by its $\sim 6$ times higher transcriptional activity in somatic S-100 extracts (Gouilloud and Clarkson 1986). Thus, it possesses many of the features that might be expected for a somatic-type gene.
In the work presented here we used synthetic oligonucleotides to analyze the sequence and steady-state levels of unspliced tyrosine tRNA precursors during early development. The results indicate that the TyrC and TyrD genes are indeed oocyte type and somatic type, respectively, but that there are additional genes of each class. We describe some sequence features of these genes and compare the developmental changes of tyrosine tRNA with the oocyte-somatic switch of 5S RNA.

\section{Results}

RNA sequences and oligonucleotide probes that distinguish the TyrC and TyrD transcripts

Figure 1 shows a comparison of the transcription products of the TyrC and TyrD genes in S-100 extracts of cultured $X$. laevis kidney cells (Gouilloud and Clarkson 1986). Transcription of TyrC starts with a pppAp located 5 nucleotides before the mature coding sequence, and it terminates at many of the $T$ residues within a downstream $\mathrm{T}_{3} \mathrm{GT}_{4}$ stretch to yield primary transcripts of 97-102 nucleotides (Pre-tRNA 1, Fig. 1). These precursors are converted to a processing intermediate of 89 nucleotides that contains mature $5^{\prime}$ and $3^{\prime}$ ends (Pre-tRNA 2); the 13-nucleotide intervening sequence then is removed by splicing and ligation reactions to yield the mature length tRNA of 76 nucleotides.

TyrD produces primary transcripts of $\sim 101$ nucleotides that contain a $5^{\prime}$ leader of 7 nucleotides, an intervening sequence of 12 rather than 13 nucleotides, an $\mathrm{A}$ 
rather than a $\mathrm{G}$ at position 57 of the coding region, and 3 ' trailer sequences that end within the first 2-4 residues of a $\mathrm{T}_{15}$ stretch. A second initiation site, an $\mathrm{A}$ at -3 , gives rise to a minor fraction of TyrD primary transcripts of $\sim 97$ nucleotides. These precursors are converted to a correspondingly shorter processing intermediate of 88 nucleotides and then to the mature tRNA.

Figure 1 also shows some of the oligonucleotide probes that were used to examine the kinds of tRNA gene transcripts made in vivo. Oligonucleotides $\mathrm{Cl}$ and D1 are specific for the intervening sequences of $\mathrm{TyrC}$ and TyrD, respectively. Under appropriate conditions, they should anneal only to the complementary unspliced precursors. The tyrosine coding sequence probe Ml should detect the same precursors, and any additional ones, together with the mature tRNA ${ }^{\text {Tyr. }}$. These three probes range in length from 25-28 nucleotides and were designed to yield RNA-DNA hybrids of comparable stabilities, assuming that a G-C base pair is twice as stable as an A-T base pair (Suggs et al. 1981).

\section{TyrC is an oocyte-type gene and TyrD is a} somatic-type gene

When incubated with Northern blots of total ovary $\mathrm{RNA}$, oligonucleotide $\mathrm{Cl}$ anneals to a heterogeneous set of RNAs of $\sim 100$ nucleotides and to a shorter, apparently unique RNA species of $\sim 90$ nucleotides (Fig. 2, lane $\mathrm{cl}$. Thus, these precursors correspond in both sequence and length to the TyrC primary transcripts and to their processing intermediate. Oligonucleotide M1 hybridizes to these same precursors and also yields the expected strong signal in the mature tRNA region (Fig. 2 , lane $b$ ); however, none of these bands is detected by the TyrC intron probe in RNA from cultured kidney cells (Fig. 2, lane f). These results suggest that the highly repeated TyrC genes are active in oogenesis but that their expression is repressed in somatic cells.

Conversely, the TyrD intron probe hybridizes weakly to a single precursor band in the kidney cell RNA and fails to give a signal with ovarian RNA (cf. lane $g$ with lane d, Fig. 2). From the mobilities of internal labeled markers in the Northern blots (data not shown), this somatic precursor also has a length of $\sim 100$ nucleotides. Oligonucleotide M1 gives a much stronger signal with RNAs of this length, together with an intense band that corresponds to mature tRNA ${ }^{\mathrm{Tyr}}$ (Fig. 2, lane e). This probe also hybridizes to a group of kidney cell RNAs of $\sim 90$ nucleotides; these molecules presumably represent tRNA $^{\text {Tyr }}$ precursors that either lack an intervening sequence or contain one that differs from the one within TyrD. Thus, these results indicate that $\mathrm{TyrD}$ is a minor somatic-type gene and that most of the kidney cell tRNA ${ }^{\text {Tyr }}$ precursors are derived from a different set of somatic-type tyrosine tRNA genes. It is possible that TyrD also is expressed during oogenesis but that, because of its much lower copy number than TyrC, its transcripts are undetectable.

\section{TyrC is one of two $t R N A^{T y r}$ genes expressed in the ovary}

A direct way to characterize these various transcripts is to anneal the oligonucleotides with the RNA samples in solution, to extend the primers with reverse transcriptase and then to sequence the extended products. This is not straightforward technically because the substrates are present in low amounts, and they contain a high degree of structure and some modified bases, both of which cause frequent premature termination. The cDNA yield can be maximized, however, by use of a primer such as M1 that is complementary to sequences near the $5^{\prime}$ end of the mature tRNA.

Figure 3 shows the reverse transcriptase products obtained from ovary tRNA precursors primed with oligonucleotide M1, together with sequence analysis of some of the longer cDNAs. Band D contains the 25-nucleotide primer and an additional 11 nucleotides that are complementary to the first 11 nucleotides of mature tyrosine

\section{TyrC}

Pre-tRNA 1:

Pre-tRNA 2:

Mature tRNA:

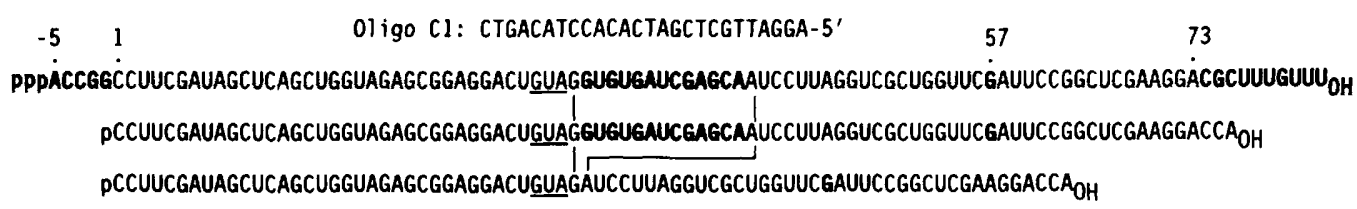

01 igo M1: AGTCGACCATCTCGCCTCCTGACAT-5'

01 igo M2: AGGCCGAGCTTCCT-5'

\section{TyrD}

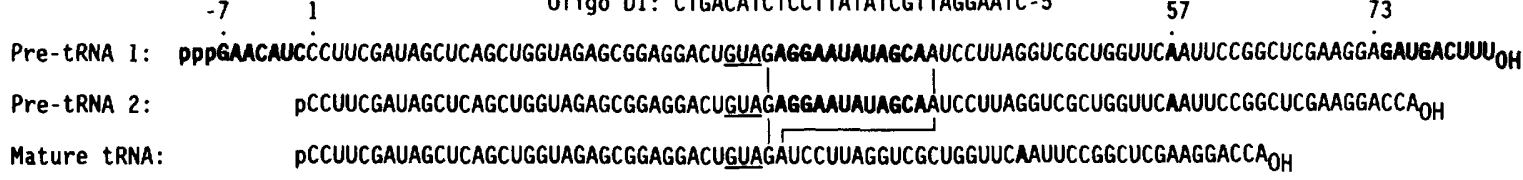

01 igo Ml: AGTCGACCATCTCGCCTCCTGACAT-5'
01 igo M2: AGGCCGAGCTTCCT-5,

Figure 1. Transcripts and oligonucleotides specific for the $T y r C$ and $T y r D$ genes. The unspliced precursors and oligonucleotide probes are aligned with the $5^{\prime}$ end of the mature tRNA ${ }^{\text {Tyr }}$ produced from each gene. Nucleotides are numbered according to the convention for tRNAs and their genes (Sprinzl et al. 1987). Transcripts are shown in their unmodified form and the anticodon is underlined. The $5^{\prime}$ leaders, intervening sequences, and the purines at position 57 are shown in boldface type. 


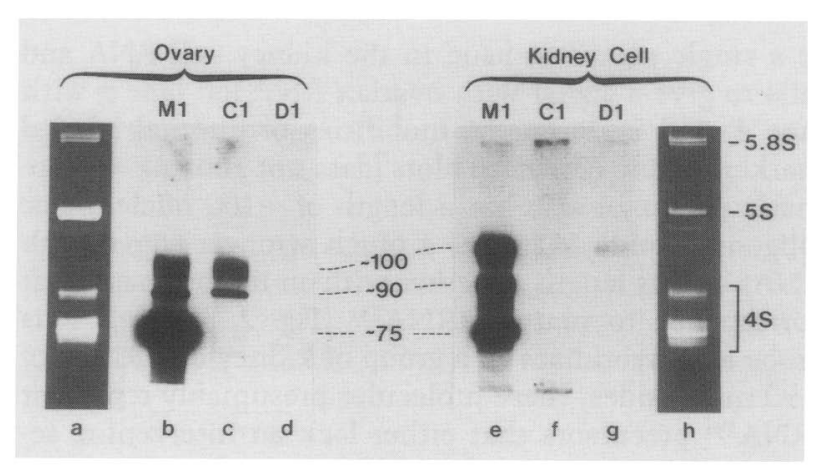

Figure 2. Northern blot analysis of $X$. laevis ovary and kidney cell RNA. Samples of total RNA from ovary tissue and from cultured kidney cells were fractionated over two wide slots of a thick sequencing gel and were transferred electrophoretically to a nylon membrane. The region of the filter that contained RNA sample was cut into strips, and pairs of strips, one from each sample, were hybridized with the 5'-labeled oligonucleotide probes (lanes $b-d$ and $e-g$ ). Exposures were for 1 day at $-70^{\circ} \mathrm{C}$ on preflashed film with an intensifying screen. The ethidium fluorescence of RNA samples electrophoresed under identical conditions is shown (lanes $a$ and $h$ ). Some uncharacterized components, possibly polysaccharides, that migrate between ovary 5S and 4S RNA cause the anomalously fast mobilities of the tRNA precursors.

tRNA; presumably this cDNA is not derived from the mature tRNA ${ }^{\mathrm{Tyx}}$, which was removed by prior gel electrophoresis, but rather from tRNA ${ }^{\mathrm{Tyr}}$ precursors that have undergone $5^{\prime}$-end processing.

The longer cDNAs are extension products of tRNA ${ }^{\mathrm{Tyr}}$ precursors with $5^{\prime}$ leaders. Band $\mathrm{B}$ contains an extra 5 nucleotides $\left(5^{\prime}\right.$-CCGGT-3' that are precisely complementary to the $5^{\prime}$ leader sequence of the longest TyrC transcripts made in vitro. Thus band $B$ is identified as the cDNA product of TyrC primary transcripts. Band $C$ is a truncated version of $B$ that contains 3 of these $5 \mathrm{nu}$ cleotides $\left(5^{\prime}-\mathrm{CCG}-3^{\prime}\right)$. This cDNA could arise through partial degradation of the TyrC primary transcripts or their incomplete copying; it seems unlikely that it represents a full-length copy of a primary transcript because this would imply initiation with a pppCp. Thus, these results provide direct evidence for the TyrC gene transcripts in the ovary.

Sequence analysis of band A (Fig. 3) has revealed the presence of another kind of tyrosine tRNA precursor in this tissue. This cDNA contains the 36 nucleotides characteristic of tRNA ${ }^{\mathrm{Tyr}}$ plus an additional 7 nucleotides that are not complementary to the $5^{\prime}$ leaders of either TyrC or TyrD primary transcripts. Apart from uncertainty about the last residue, this sequence appears to be unique $\left(5^{\prime}\right.$-CAGGAGN-3'). Thus, band $\mathrm{A}$ is derived from transcripts of a second type of RNA $^{\mathrm{Tyr}}$ gene that is expressed in the ovary; moreover, the failure to detect longer cDNAs suggests that band $A$ is the cDNA product of its primary transcripts.

The two tRNA $A^{T y r}$ genes expressed in the ovary contain different intervening sequences

TyrC precursors contain a 13-nucleotide intervening se- quence and a $G$ at position 57 of the mature tRNA (Fig. 1). To determine whether these features are found also in the other ovarian tyrosine tRNA precursors, an oligonucleotide complementary to the last 14 nucleotides of mature tRNA ${ }^{\mathrm{Tyr}}$ (oligonucleotide M2, Fig. 1) was used for primer extension analysis. Reactions with this primer are particularly inefficient because the reverse transcriptase has to copy almost the entire highly structured tRNA moiety of the precursors. Nevertheless, some full-length cDNAs are obtained that, when sequenced (Fig. 4), exhibit a unique $C$ that corresponds to position 57 of mature tRNA. Thus, the absence of a strong $T$ reaction suggests that a $G$ occupies this position in both kinds of ovarian tRNA ${ }^{\mathrm{Tyr}}$ precursors.

The remainder of the cDNA sequence is unique also, and complementary to tyrosine tRNA, except for the presence of some double reactions within the region that corresponds to the intervening sequence of TyrC (Fig. 4). This implies that the two kinds of tRNA ${ }^{\text {Tyr }}$ precursors contain intervening sequences of the same length (13 nucleotides) but that they differ in some positions. The intervening sequence within the second ovarian tRNA $^{\text {Tyr }}$ precursor may be deduced by subtracting that of TyrC; because of a suboptimal $C$ reaction, the deduced sequence is not unambiguous but it is clear that the two intervening sequences differ in at least two positions (Figs. 4 and 5 ).

\section{A fourth kind of $t R N A^{T y r}$ gene is expressed in somatic cells}

Primer extension sequencing was used similarly to analyze the nature of the unspliced tRNA ${ }^{\mathrm{Tyr}}$ precursors synthesized in cultured kidney cells. Oligonucleotide M1 yields a series of cDNAs that extend beyond the $5^{\prime}$ end of the mature tRNA; unlike their ovary counterparts, these cDNAs appear to be derived from a major set of tRNA $^{\text {Tyr }}$ precursors that contain just one kind of $5^{\prime}$ leader sequence (data not shown). The longest cDNA contains an extra 7 nucleotides $\left(5^{\prime}\right.$-CTTGATN-3') that is not complementary to the $5^{\prime}$ leaders of TyrD, TyrC, or the other ovarian precursors. The sequences characteristic of this novel 5 ' leader also are found in full-length extension products of the M2 primer (Fig. 4). More clearly visible in this particular gel is the unique $T$ reaction at a position complementary to $R_{57}$ of the mature tRNA. The major somatic transcripts therefore contain an $\mathrm{A}$ residue at this position. They also possess a 13-nucleotides intervening sequence (Fig. 4) that is different from the 12-nucleotides intron within TyrD.

Hence cultured kidney cells transcribe a fourth type of tRNA $^{\text {Tyr }}$ gene that is distinct from TyrD and from the two kinds of genes that are expressed in the ovary. The results imply further that both kinds of genes active in the ovary, and not merely TyrC, are repressed in somatic cells. The primer extension analyses are summarized in Figure 5, which aligns the noncoding DNA strands of the two oocyte-type and two somatic-type genes. 


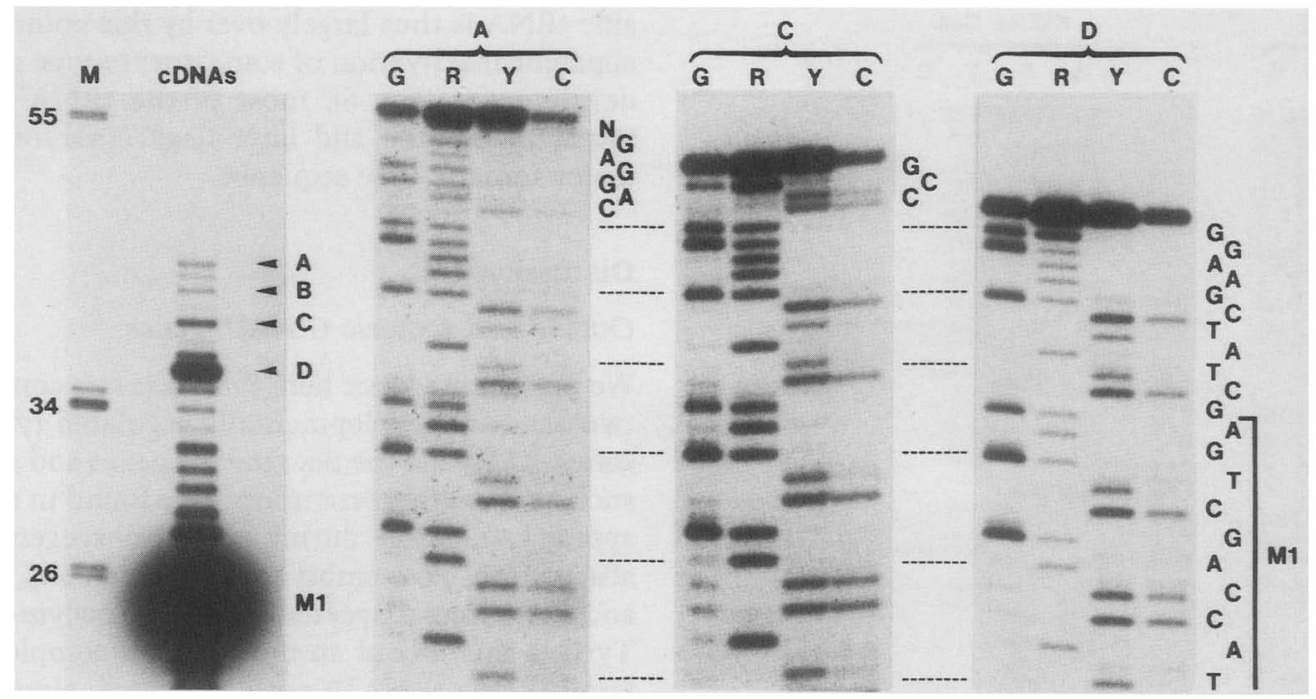

Figure 3. Primer extension analysis of the $5^{\prime}$ leaders within ovary tRNATyr precursors. Ovary RNAs that migrated between $5 S$ RNA and mature tRNA on a thick sequencing gel were recovered, annealed with $5^{\prime}$-labeled oligonucleotide $\mathrm{M} 1$, and extended with AMV reverse transcriptase. (Left) The cDNA products fractionated on an analytical gel are shown; (lane $M$ ) MspI digest of GEM4 plasmid DNA, with fragment lengths given in units of base pairs. The arrowed bands were recovered from a preparative gel and were sequenced by the chemical method. The $3^{\prime}$ end of the M1 primer is shown beside the sequence gel of band D. Only nucleotides extending beyond the $5^{\prime}$ end of the mature tRNA ${ }^{\mathrm{Tyr}}$ are shown beside the sequence gels of bands $\mathrm{A}$ and $\mathrm{C}$. The analytical gel was exposed for $12 \mathrm{hr}$; sequence gels were exposed for 10 days at $-70^{\circ} \mathrm{C}$ to preflashed film and an intensifying screen.

\section{Developmental expression of oocyte-type and somatic-type genes}

To determine when the TyrC, TyrD, and major somatictype genes are expressed during development, Northern blots of total RNA from staged oocytes (Dumont 1972) and embryos (Nieuwkoop and Faber 1967) were annealed with oligonucleotides $\mathrm{M} 1, \mathrm{Cl}$, and D1 (Fig. 1) and a fourth probe, oligonucleotide S1 (Fig. 5). From the primer extension sequencing results, this new probe should be specific for the intervening sequence of the major somatic-type tRNA ${ }^{\mathrm{Tyr}}$ precursors.

Tyrosine tRNA precursors are very difficult to detect in oocytes under conditions that readily reveal the precursors in gastrula and later stage embryos (Fig. 6). With increased RNA amounts and longer exposure times, however, tRNA ${ }^{\text {Tyr }}$ precursors of $\sim 100$ and $\sim 90$ nucleotides can be detected in stage I oocytes with oligonucleotides M1 (Fig. 6) and Cl (data not shown). Therefore, these precursors include unspliced transcripts of the TyrC genes. From the pattern of hybridization with oligonucleotide Ml, their steady-state levels remain roughly constant from stages I-IV and then decrease in stages V and VI. These results suggest that at least the TyrC oocyte-type genes are expressed very early during oogenesis and that changes occur in the synthesis, processing, or degradation of their transcripts as the oocyte nears maturation. In contrast, the D1 and S1 probes give no detectable signal with RNA from staged oocytes or from ovary tissue under conditions that yield a strong $\sim 100$ nucleotide band in kidney cell RNA (Fig. 2 and data not shown). This implies either that somatic-type transcripts are not synthesized during oogenesis or, if they are made, that they account for a very minor fraction of the oocyte tRNA ${ }^{\text {Tyr }}$ precursor population.

No tRNA ${ }^{\text {Tyr }}$ precursors are found between fertilization and early blastula (stage 8) with any of the four probes, even after long exposures of blots that contain large amounts of RNA (data not shown). The Ml probe detects the mature tRNA ${ }^{\mathrm{Tyr}}$ readily, however, which remains roughly constant per embryo during these early synchronous cleavage stages (Fig. 6). The hybridization patterns then change dramatically after the midblastula transition (MBT). Oligonucleotide M1 first detects tRNA $^{\text {Tyr }}$ precursors at late blastula (stage 9); their steady-state levels are very high in gastrula embryos, with a peak at stage 10 , and then drop sharply in neurula and tail-bud stages. A second phase of $\mathrm{tRNA}^{\mathrm{Tyr}}$ precursor accumulation then commences at around the time of hatching (Fig. 6).

The TyrC precursors are detected first at stage 9, they reach a maximum at stage 10 , decline at the end of gastrulation, and are not found in late neurula and tail-bud stages; they then reappear in low amounts after hatching (Fig. 6). The major somatic-type tRNA ${ }^{\text {Tyr }}$ precursors first appear at stage 10, and they peak at late gastrula (stage 12); they also decline to some extent at the end of gastrulation but are still present in neurula stages; they then exhibit their greatest accumulation in tadpoles (Fig. 6). The TyrD precursors follow the same pattern but they are present in at least 10-fold lower amounts (Fig. 6; note the 5 times longer exposure of the D1 blot).

To try to confirm and extend these Northern blot analyses, primer extension sequencing was applied to RNA from selected embryonic stages. With RNA from stage-10 embryos, the M1 primer generates cDNAs that 


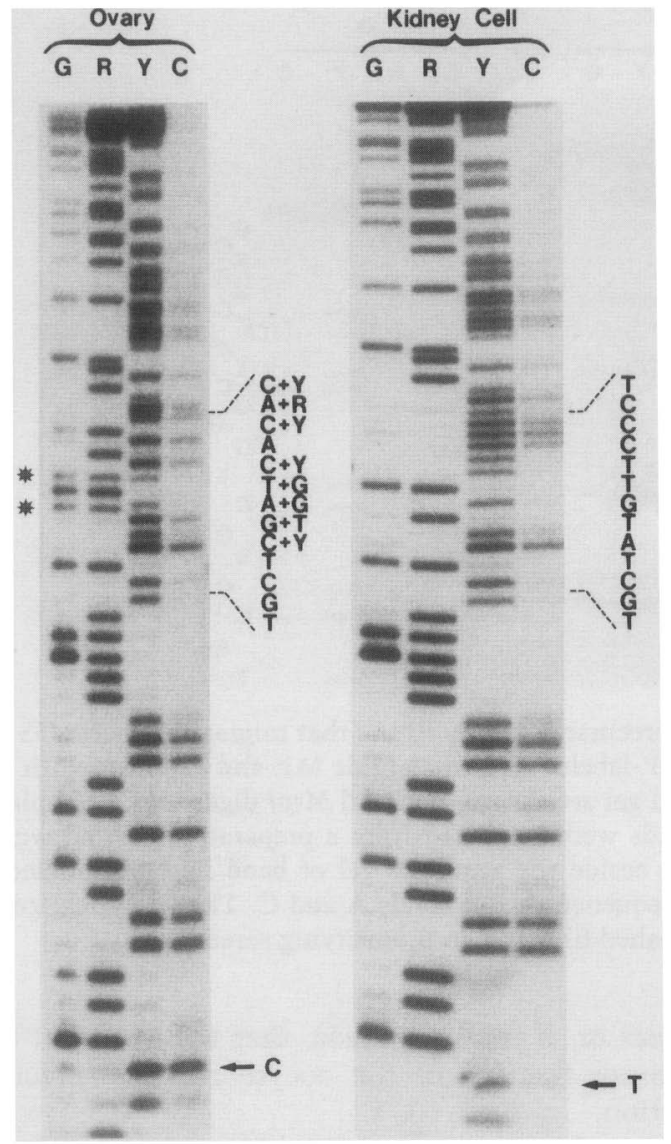

Figure 4. Primer extension analysis of the intervening sequences within ovary and kidney cell tRNA ${ }^{\mathrm{Ty}}$ precursors. Total RNA samples from ovary and from cultured kidney cells were annealed with 5'-labeled oligonucleotide M2 and were extended with AMV reverse transcriptase. The cDNA products that extended beyond the $5^{\prime}$ end of mature tRNA ${ }^{\text {Tyr }} \mid>86 \mathrm{nu}-$ cleotides) were recovered from a preparative gel and were sequenced by the chemical method. Nucleotides complementary to the introns are shown beside each sequence gel. Stars indicate the mixed $G+T$ reactions in the ovarian intron cDNAs; other possible double reactions are listed beside the TyrC intron cDNA sequence. Arrows denote nucleotides complementary to the purine at position 57 of mature tRNA ${ }^{\mathrm{Tyr}}$. Exposures were for 14 days at $-70^{\circ} \mathrm{C}$ on preflashed film with an intensifying screen.

are identical in length and sequence to those produced from ovary RNA (data not shown). Thus, both kinds of tRNA $^{\text {Tyr }}$ genes expressed in the ovary, and not merely TyrC, are also active in gastrula stage embryos. Moreover, the two kinds of oocyte-type transcripts account for the vast majority of the tRNA ${ }^{\mathrm{Ty}}$ precursors present at this stage.

In contrast, the $\mathrm{M} 1$ primer yields cDNA sequences from embryonic stages $38,24-26,18-20$, and 14-16 that are of the major somatic-type exclusively /data not shown). This implies that the very abundant oocyte-type transcripts found in stage-10 and stage- 12 embryos are processed or degraded by the beginning of neurulation. The switch from the oocyte-type to somatic-type tyro- sine tRNA is thus largely over by this point. Despite the apparent reactivation of some oocyte-type genes later in development (Fig. 6), most of the tRNA ${ }^{\mathrm{Tyx}}$ precursors found in neurula and later-stage embryos exhibit the major somatic-type sequence.

\section{Discussion}

Oocyte and somatic $t R N A^{T y r}$ genes

We present evidence here that $X$. laevis contains at least two kinds of developmentally regulated tyrosine tRNA genes. These are the oocyte-type genes and are defined as such because their transcripts are found in oocytes; they appear transiently during early embryogenesis, but are absent from post-embryonic somatic cells (Figs. 2, 3, 4, and 6). As long suspected, one of the oocyte-type genes is TyrC, a member of an unusual and complex multigene family. This tRNA ${ }^{\mathrm{Tyr}}$ gene is located, along with seven other tRNA genes, on tandemly repeated 3.18-kb DNA fragments at a single chromosomal locus (Müller and Clarkson 1980; Fostel et al. 1984; Müller et al. 1987). Although direct evidence is as yet lacking, it seems highly probable that all eight genes on these repeats also are regulated developmentally and are of the oocyte type.

Information on the second oocyte-type tRNA ${ }^{\text {Tyr }}$ gene is more limited but, from the sequence gel shown in Figure 4, it's transcripts appear to be almost as abundant in ovary RNA as those of the TyrC genes. It seems reasonable to suppose that these transcripts also are derived from highly repeated genes. A possible candidate for their location is a second cluster of tandemly repeated DNA fragments that contain several tRNA genes (Rosenthal and Doering 1983). Originally, these $3.1-\mathrm{kb}$ repeats were thought to represent a minor tRNA gene cluster, but current estimates suggest that there are $\sim 800$ copies of the $3.1-\mathrm{kb}$ repeats and $\sim 200$ copies of the 3.18 -kb repeats per haploid $X$. laevis genome (J.L. Doering, pers. comm.). Clearly, it will be of interest to determine whether the $3.1-\mathrm{kb}$ repeats contain a tRNA ${ }^{\mathrm{Tyr}}$ gene and, if so, whether this gene matches the second oocyte-type sequence shown in Figure 5.

The two other genes discussed here are designated somatic-type. Their transcripts are not found during oogenesis, perhaps because they are below the detection limit of the present methods, but they are seen clearly from the gastrula stage onward and in postembryonic somatic cells (Figs. 2, 4, and 6). The TyrD gene, present in only 1-3 copies per haploid genome, is transcribed very actively in somatic S-100 extracts /Gouilloud and Clarkson 1986), yet in vivo it gives rise to only a minor fraction of somatic-type transcripts. The major fraction is derived from another kind of gene whose unspliced precursors exhibit unique $5^{\prime}$ leader and intervening sequences (Figs. 4 and 5). Taken together, these results suggest that the major somatic-type transcripts are not derived from a single copy gene, but rather from a small family of $\sim 20-50$ highly conserved genes. Nothing is known yet of their organization, but they should be selectable with the oligonucleotide S1 probe (Fig. 5). 
Major 0ocyte-type (TyrC): Second 0ocyte-type: CCACCGGCCTTCGATAGCTCAGCTGGTAGAGCGgAGGACTGTAGgTGTGATCGAGCAATCCTTAGGTCGCTGGTTCGATTCCGGCTCGAGGA
NCTCCTGCCTTCGATAGCTCAGCTGGTAGAGCGGAGGACTGTAGRYRTRCCARAGCAATCCTTAGGTCGCTGGTTCGATTCCGGCTCGAAGGA
[GTGTGCCAGAGCA]

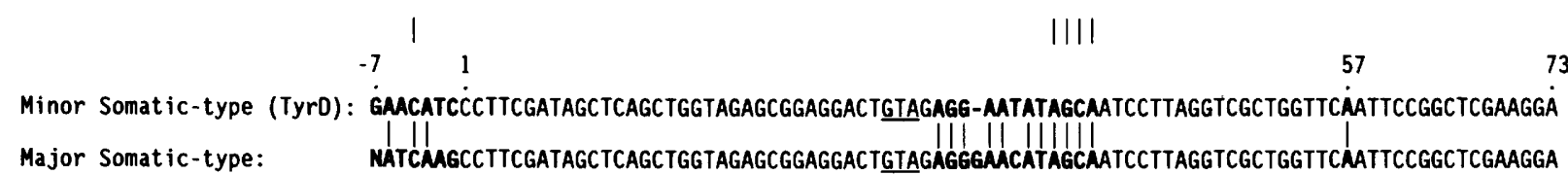

01 igo S1: CTGACATCTCCCTTGTATCGTTAGGAA-5'

Figure 5. The sequences of the four known $X$. laevis tRNA ${ }^{\mathrm{Tyr}}$ genes. The noncoding DNA strands of TyrC (Müller and Clarkson 1980) and TyrD (Gouilloud and Clarkson 1986) are aligned with those of the two new tRNA ${ }^{\text {Tyr }}$ genes inferred from primer extension sequencing. The anticodon is underlined. The $5^{\prime}$-flanking regions, intervening sequences, and the purines at position 57 are shown in boldface type; vertical bars depict identical nucleotides within these three regions. The intron within the second oocyte-type gene contains several ambiguous positions; the sequence considered most likely is enclosed in brackets. Oligonucleotide S1 is the probe designed to be specific for the major somatic-type tRNA ${ }^{T y r}$ precursors.

The $5^{\prime}$-flanking sequences of the two oocyte-type genes are somewhat related, as are the comparable regions of the two somatic-type genes (Fig. 5). The intervening sequences within each pair of genes are even more similar, with an 11 out of 13 match for the somatic-type pair and perhaps as much as 10 out of 13 match for the oocyte-type pair. In addition, all four intervening sequences are identical in the last four posi-

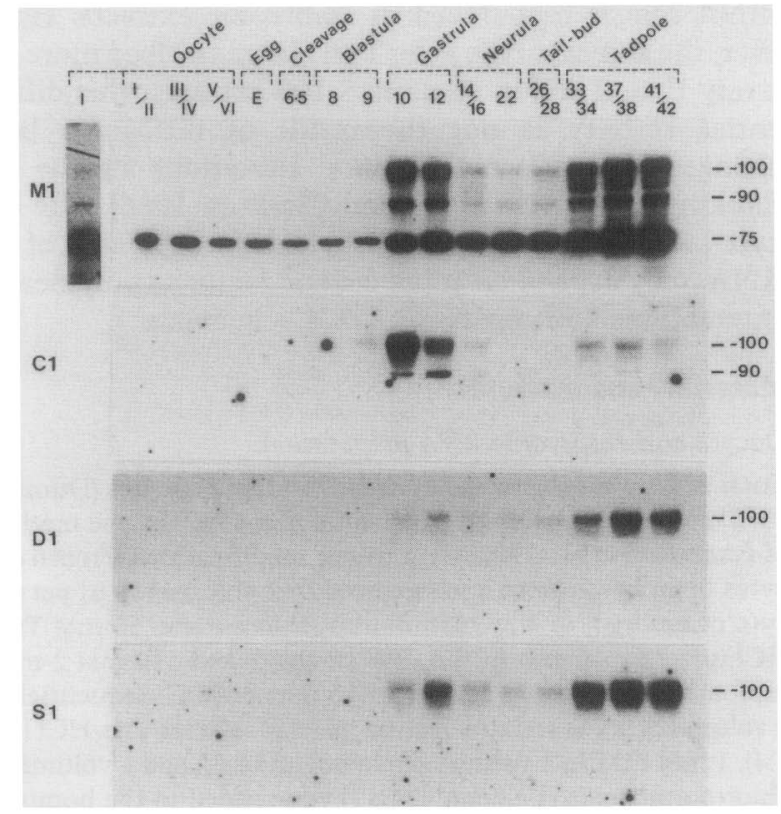

Figure 6. Northern blot analysis of RNA during oogenesis and embryogenesis. Total RNA samples from the equivalent of one oocyte, egg, or embryo at the indicated developmental stages were fractionated on thick sequencing gels. After electrophoretic transfer to nylon membranes, the blots were hybridized with the indicated $5^{\prime}$-labeled oligonucleotide probes. The M1, $\mathrm{Cl}$, and $\mathrm{S} 1$ blots were exposed at $-70^{\circ} \mathrm{C}$ for 1 day, and the D1 blot for 5 days, to preflashed film with an intensifying screen. (Lane 1, top) Blot of RNA from 10 stage-I oocytes probed with oligonucleotide $\mathrm{M} 1$ and exposed for 5 days. tions (AGCA, Fig. 5). As noted previously for the TyrC and TyrD transcripts (Gouilloud and Clarkson 1986), these sequences would preclude base-pairing with the entire anticodon, thereby yielding a more open structure than that found in unspliced tRNA precursors from yeast. The presence of these same four nucleotides in two more $X$. laevis tRNA ${ }^{\mathrm{Tyr}}$ genes indicates that these sequences are under strong selective pressure. Although recent evidence suggests that the intron sequence is unimportant for the splicing of yeast tRNA precursors by the Xenopus endonuclease (Mattoccia et al. 1988), this enzyme may still have a preference for the sequence or for the more open structures of its homologous substrates.

There are indications, however, that the oocyte-type and somatic-type tRNA ${ }^{\mathrm{Tyr}}$ precursors are not spliced with equal efficiency. The oligonucleotide $\mathrm{Cl}$ probe detects precursors of $\sim 100$ nucleotides and $\sim 90$ nucleotides that are identified as the TyrC primary transcripts and their unspliced processing intermediates, respectively, whereas the somatic-specific D1 and S1 probes reveal only $\sim 100$ nucleotide precursors (Figs. 2 and 6). Thus, splicing appears to be the rate-limiting processing step for oocyte-type transcripts but not for somatic-type precursors. This may reflect sequence differences in their introns or the purine transition at position 57 of the coding sequence (Fig. 5).

\section{Developmental changes in $t R N A^{\text {Tyr }}$ and $5 S$ RNA}

Transcription is repressed after breakdown of the oocyte nuclear membrane at meiosis, and it remains inactive after fertilization and during the early synchronous cleavage stages of embryogenesis (Newport and Kirchner 1982, and references therein). When embryos are labeled with $\left[\alpha^{-32} \mathrm{P}\right] \mathrm{GTP}$, new tRNA synthesis is found first at the MBT, stage 8 (Wakefield and Gurdon 1983). Northern blot analysis, which measures RNA steadystate levels rather than synthesis, first detects new tRNA $^{\text {Tyx }}$ precursors at late blastula, stage 9, and these are predominantly oocyte-type; the two kinds of somatic-type precursors appear somewhat later, at stage 10 
(Fig. 6). Taken together, these results suggest that all four kinds of tRNA ${ }^{\mathrm{Tyr}}$ genes are activated at or soon after the MBT, and that the delays result from the time needed to accumulate detectable amounts of their unspliced transcripts. Presumably this activation is not just tyrosine specific but applies to oocyte-type and somatic-type genes for all tRNA species.

Transcripts of all four kinds of tRNA ${ }^{\text {Tyr }}$ genes accumulate in gastrula stage embryos; a decrease then occurs in the steady-state levels of all precursor forms, but particularly of the oocyte-type transcripts, and most of the tRNA ${ }^{\text {Tyr }}$ precursors are somatic-type by the onset of neurulation (Fig. 6). Although these results do not define when this oocyte-somatic switch occurs at the transcriptional level, blastula and early gastrula embryos synthesize tRNA at high rates (Wakefield and Gurdon 1983), whereas transcription of tRNA genes in isolated chromatin decreases by the end of gastrulation (Andrews and Brown 1987). Thus, it seems likely that the oocytetype genes are activated first at the MBT and then are repressed preferentially by the midgastrula stage. Consistent with this suggestion, oocyte-type transcripts are most abundant at stage 10, in which they constitute the great majority of the tRNA ${ }^{\mathrm{Tyr}}$ precursor population, whereas the somatic-type transcripts accumulate somewhat later, at stage 12 (Fig. 6). A second major transition then occurs at the hatching stage, which seems to involve a reactivation of some oocyte-type genes and an increased synthesis or stabilization of both kinds of somatic-type precursors (Fig. 6).

The pattern of expression of tRNA ${ }^{\mathrm{Tyr}}$ genes resembles that of the $X$. laevis 5S RNA genes, in which the 5S RNA population changes from predominantly oocytetype during oogenesis to somatic-type by the end of gastrulation. The two phenomena differ, however, in at least one important respect. The 5S RNA synthesized in late blastulae comprises a nearly equal mixture of oocyte-type and somatic-type transcripts, which indicates that most of the highly repeated oocyte-type 5S RNA genes are normally not transcribed after oocyte maturation (Wormington and Brown 1983; Wakefield and Gurdon 1983). In contrast, the tRNA ${ }^{\text {Tyr }}$ precursors that are first detectable after the MBT are predominantly oocyte-type (Fig. 6), which may suggest that all of the oocyte-type tRNA ${ }^{\text {Tyr }}$ genes are activated first and then are repressed selectively. A second potential difference is that some oocyte-type tRNA ${ }^{\mathrm{Tyr}}$ genes are expressed in tadpoles (Fig. 6); oocyte-type 5S RNA has not been described in these late stages. Finally, and again in apparent contrast to 5S RNA, the present work failed to detect somatic-type tRNA ${ }^{\text {Tyr }}$ precursors in oocytes.

Several mechanisms have been proposed to account for the selective inactivation of the oocyte-type 5S RNA genes. Early models emphasized the importance of the decreasing amounts of the 5S-specific factor TFIIIA during embryogenesis, the early replication of the somatic-type genes, and their greater affinity for TFIIIA (for review, see Brown 1984). All of these have been found wanting in some respects: Oocyte-type 5S RNA repression can occur in the presence of an excess of
TFIIIA and in the absence of DNA synthesis (Andrews and Brown 1987), and the major oocyte and somatic genes have equal affinities for TFIIIA (McConkey and Bogenhagen 1988). More recent work suggests that oocyte-type transcription complexes are selectively destabilized in somatic cells, and that a limitation of common RNA polymerase III transcription factors can contribute to this destabilization (for review, see Wolffe and Brown 1988). This partly reflects sequence differences in the internal promoters, but sequences farther upstream also contribute to the differential transcription of oocyte and somatic 5S RNA genes in vitro (Reynolds and Azer 1988).

Some of these mechanisms may function in oocytetype tRNA ${ }^{\text {Tyr }}$ gene repression but an involvement of TFIIIA seems unlikely. This factor is not needed for the transcription of tRNA genes by RNA polymerase III (Lassar et al. 1983), and elevated levels of TFIIIA in developing embryos stimulate 5S RNA synthesis at the MBT but are without effect on tRNA synthesis (Andrews and Brown 1987). These results imply further that two common factors required for 5S RNA and tRNA synthesis, TFIIIB and TFIIIC, are not limiting in early embryogenesis, which may help to explain the very high levels of the oocyte-type tRNA ${ }^{\text {Tyr }}$ precursors found in gastrulae (Fig 6). Whether factor levels then decrease and contribute to the inactivation of the oocyte-type tRNA ${ }^{\text {Tyr }}$ genes, is not yet known. Also, it is not known yet whether the oocyte-somatic switch of tyrosine tRNA can be reproduced in embryonic extracts. However, the somatic-type gene TyrD is transcribed more actively than TyrC in somatic S-100 extracts; this differential activity is not the result of intragenic base changes but reflects sequence alterations in the $5^{\prime}$ flanking DNA (Gouilloud and Clarkson 1986). The oocyte-switch of tyrosine tRNA, and perhaps also of $5 \mathrm{~S}$ RNA, may depend on some critical factor or polymerase interactions with upstream DNA sequences.

\section{Materials and methods}

\section{Oocyte and embryonic RNA preparation}

Total RNA was isolated from $X$. laevis staged oocytes (Dumont 1972) and embryos (Nieuwkoop and Faber 1967) by the method of Feramisco et al. (1982) with minor modifications. Frozen oocytes or embryos were homogenized in 1 volume $(20 \mu 1$ per oocyte or embryo) of $4 \mathrm{M}$ guanidinium thiocyanate, $50 \mathrm{~mm}$ Tris$\mathrm{HCl}(\mathrm{pH} 7.6), 10 \mathrm{~mm}$ EDTA, 2\% sarcosyl, and $140 \mathrm{~mm}$ 2-mercaptoethanol and were heated for $15 \mathrm{~min}$ at $60^{\circ} \mathrm{C}$. Sequentially, 1 volume of $0.1 \mathrm{~m}$ sodium acetate (pH 5.2), $10 \mathrm{~mm}$ Tris- $\mathrm{HCl}$ (pH 7.4), $1 \mathrm{~mm}$ EDTA, 1 volume of phenol ( $\mathrm{pH} 8.0$ ), and 1 volume of chloroform-isoamyl alcohol $(24: 1)$ were added to the homogenate. Samples were left for another $10 \mathrm{~min}$ at $60^{\circ} \mathrm{C}$ with intermittent shaking and then were centrifuged. Each aqueous phase was reextracted once with 1 volume of phenol plus 1 volume of chloroform-isoamyl alcohol, and once with 2 volumes of chloroform-isoamyl alcohol. RNA samples were recovered by ethanol precipitation at $-20^{\circ} \mathrm{C}$ and were resuspended in water.

\section{Northern blot analyses}

Total RNA from 1-10 oocyte or embryo equivalents was dried down, resuspended in $7 \mathrm{M}$ urea, $0.25 \times$ TEB $(1 \times$ is $50 \mathrm{mM}$ Tris- 
$\mathrm{HCl}, 50 \mathrm{~mm}$ boric acid, $1 \mathrm{~mm}$ EDTA) and fractionated on 2-mm thick $8 \%$ polyacrylamide $-7 \mathrm{M}$ urea gels in $1 \times$ TEB. Gels were stained for $20 \mathrm{~min}$ in transfer buffer [ $12 \mathrm{mM}$ Tris, $6 \mathrm{mM}$ sodium acetate, $0.3 \mathrm{mM}$ EDTA $(\mathrm{pH} 7.5)]$ that contained $1 \mathrm{mg} / \mathrm{ml}$ of ethidium bromide, photographed, then soaked for $25 \mathrm{~min}$ in fresh transfer buffer with slow agitation. The RNA was transferred to a nylon membrane (Zeta probe, Bio-Rad) by semi-dry blotting (Kyhse-Anderson 1984) by use of a Multiphor II Nova Blot System (LKB). After a 1 -hr transfer at $0.8 \mathrm{~mA} / \mathrm{cm}^{2}$, the membrane was rinsed for $30 \mathrm{~min}$ in transfer buffer, baked for 2 $\mathrm{hr}$ at $80^{\circ} \mathrm{C}$, and then prehybridized for $4 \mathrm{hr}$ at $39^{\circ} \mathrm{C}$ in $0.9 \mathrm{M}$ $\mathrm{NaCl}, 50 \mathrm{~mm}$ Tris- $\mathrm{HCl}$ (pH 7.5), $5 \mathrm{~mm}$ EDTA, 0.1\% $\mathrm{NaDoSO}_{4}$, and $5 \times$ Denhardt's $(1 \times$ is $0.2 \%$ each of bovine serum albumin, Ficoll and polyvinylpyrrolidine) Hybridization was carried out overnight at $39^{\circ} \mathrm{C}$ after the addition of $5-10$ pmoles of $5^{\prime}$-endlabeled oligonucleotide probe $\left(3-5 \times 10^{6}\right.$ Cerenkov $\mathrm{cpm} /$ pmole) to the prehybridization mix. Filters were rinsed 3 times in $6 \times \mathrm{SSC}, 0.1 \% \mathrm{NaDoSO}_{4}$ at room temperature, and were washed for $30 \mathrm{~min}$ at $39^{\circ} \mathrm{C}$ in $0.1 \times \mathrm{SSC}, 0.1 \% \mathrm{NaDoSO}_{4}$ then subjected to autoradiography at $-70^{\circ} \mathrm{C}$ in the presence of an intensifying screen.

\section{Primer extension analyses}

Tyrosine tRNA gene products present in $X$. laevis ovaries, cultured kidney cells, and staged oocytes or embryos were detected by primer extension analyses by use of a protocol adapted from Reeder et al. (1983) and Dingermann and Nerke (1987). In preliminary experiments with total RNA, the oligonucleotide M1 primer was found to generate a very strong cDNA from mature tRNA $^{\text {Tyr }}$ that obscured the extension products from the less abundant precursors. Consequently, the following gel purification step was employed prior to reactions with this primer. Total RNA $(200 \mu \mathrm{g})$ was electrophoresed through a $2-\mathrm{mm}$ thick $8 \%$ polyacrylamide $-7 \mathrm{M}$ urea gel, a slice corresponding to the tRNA precursor region was excised, and the RNA was recovered by electroelution and was purified further by ion-exchange chromatography (NACS Prepac columns, BRL). RNA samples were precipitated with 5 pmoles of oligonucleotide $M 1$ that had been 5 '-end-labeled with $\left[\gamma^{-32} \mathrm{P}\right] \mathrm{ATP}$ and T4 polynucleotide kinase (Boehringer) to $3-5 \times 10^{6}$ Cerenkov $\mathrm{cpm} / \mathrm{pmole}$. The dry pellets were dissolved in $30 \mu \mathrm{l}$ of $250 \mathrm{mM} \mathrm{KCl}, 10 \mathrm{mM}$ Tris-HCl (pH 8.0) and were incubated for $2 \mathrm{hr}$ at $25^{\circ} \mathrm{C}$. Primer extension was initiated by addition of $50 \mu \mathrm{l}$ of a buffer containing $24 \mathrm{mM}$ Tris- $\mathrm{HCl}$ (pH 8.0), $16 \mathrm{mM} \mathrm{MgCl}_{2}, 16 \mathrm{~mm}$ DTT, $0.4 \mathrm{~mm}$ each of dATP, dCTP, dGTP, and dTTP, $0.16 \mathrm{mg} / \mathrm{ml}$ of actinomycin D, and 20 units of AMV reverse transcriptase (Boehringer). After incubation for $30 \mathrm{~min}$ at $25^{\circ} \mathrm{C}$ and for $30 \mathrm{~min}$ at $42^{\circ} \mathrm{C}$, the cDNAs were recovered by phenol extraction and ethanol precipitation. Reactions with the M2 primer were performed in the same way except that they contained $200 \mu \mathrm{g}$ of unfractionated RNA in fourfold greater volumes. Primer extension products were fractionated on $0.5-\mathrm{mm}$ thick $12 \%$ polyacrylamide- $7 \mathrm{M}$ urea sequencing gels, selected bands were excised and eluted by diffusion in $0.5 \mathrm{M}$ ammonium acetate $(\mathrm{pH} 7.0), 1 \mathrm{mM}$ EDTA. The cDNAs were ethanol-precipitated and then sequenced by the chemical method of Maxam and Gilbert (1980).

\section{Acknowledgments}

We are indebted to D. Rungger and A. Solaro for advice and help in collecting staged oocytes and embryos, to E. Kawashima and his team at Glaxo I.M.B. for oligonucleotide synthesis, and to D. Belin and J.-D. Vassalli for critical comments on the manu- script. This work was supported by grants from the Swiss National Science Foundation.

\section{References}

Andrews, M.T. and D.D. Brown. 1987. Transient activation of oocyte $5 S$ RNA genes in Xenopus embryos by raising the level of the trans-acting factor TFIIIA. Cell 51: 445-453.

Brown, D. D. 1984. The role of stable complexes that repress and activate eukaryotic genes. Cell 37: 359-365.

Clarkson, S.G., M.L. Birnstiel, and V. Serra. 1973. Reiterated transfer RNA genes of Xenopus laevis. J. Mol. Biol. 79: 391410.

Dingermann, T. and K. Nerke. 1987. Primer extension analysis of tRNA gene transcripts synthesized in vitro and in vivo. Anal. Biochem. 162: 466-475.

Dixon, L.K. and P.J. Ford. 1982. Persistence of nonribosome bound 5S RNA in full-grown oocytes of Xenopus laevis. Dev. Biol. 91: 474-477.

Dumont, J.N. 1972. Oogenesis in Xenopus laevis (Daudin). 1. Stages of oocyte development in laboratory maintained animals. J. Morphol. 136: 153-180.

Feramisco, J.R., J.E. Smart, K. Burridge, D.M. Helfman, and G.P. Thomas. 1982. Co-existence of vinculin and a vinculin-like protein of higher molecular weight in smooth muscle. $J$. Biol. Chem. 257: 11024-11031.

Fostel, I., S. Narayanswami, B. Hamkalo, S.G. Clarkson, and M.L. Pardue. 1984. Chromosomal location of a major tRNA gene cluster of Xenopus laevis. Chromosoma 90: 254-260.

Gouilloud, E. and S.G. Clarkson. 1986. A dispersed tyrosine tRNA gene from Xenopus laevis with high transcriptional activity in vitro. I. Biol. Chem. 261: 486-494.

Kyhse-Andersen, J. 1984. Electroblotting of multiple gels: A simple apparatus without buffer tank for rapid transfer of proteins from polyacrylamide to nitrocellulose. J. Biochem. Biophys. Meth. 10: 203-209.

Lassar, A.B., P.L. Martin, and R.G. Roeder. 1983. Transcription of class III genes: Formation of preinitiation complexes. Science 222: $740-748$.

Mattoccia, E., I.M. Baldi, D. Gandini-Attardi, S. Ciafrè, and G.P. Tocchini-Valentini. 1988. Site selection by the tRNA splicing endonuclease of Xenopus laevis. Cell 55: 731-738.

Maxam, A. and W. Gilbert. 1980. Sequencing end labeled DNA with base specific chemical cleavages. Methods Enzymol. 65: 499-560.

McConkey, G.A. and D.F. Bogenhagen. 1988. TFIIIA binds with equal affinity to somatic and major oocyte 5S RNA genes. Genes Dev. 2: 205-214.

Müller, F. and S.G. Clarkson. 1980. Nucleotide sequence of genes coding for $\mathrm{tRNA}^{\mathrm{Phe}}$ and tRNA ${ }^{\mathrm{Tyr}}$ from a repeating unit of $X$. laevis DNA. Cell 19: 345-353.

Müller, F., S.G. Clarkson, and D.J. Galas. 1987. Sequence of a $3.18 \mathrm{~kb}$ tandem repeat of Xenopus laevis DNA containing 8 tRNA genes. Nucleic Acids Res. 15: 7191.

Newport, J. and M. Kirschner. 1982. A major developmental transition in early Xenopus embryos: I. Characterization and timing of cellular changes at the midblastula stage. Cell 30: $675-686$.

Nieuwkoop, P.D. and J. Faber. 1967. Normal tables of Xenopus laevis (Daudin). North-Holland, Amsterdam.

Reeder, R.H., J.G. Roan, and M. Dunaway 1983. Spacer regulation of Xenopus ribosomal gene transcription: Competition in oocytes. Cell 35: 449-456.

Reynolds, W.F. and K. Azer. 1988. Sequence differences upstream of the promoters are involved in the differential ex- 
Stutz et al.

pression of the Xenopus somatic and oocyte 5S RNA genes. Nucleic Acids Res. 16: 3391-3403.

Rosenthal, D.S. and J.L. Doering. 1983. The genomic organization of dispersed tRNA and 5S RNA genes in Xenopus laevis. J. Biol. Chem. 258: 7402-7410.

Sprinzl, M., T. Hartmann, F. Meissner, J. Moll, and T. Vorderwülbecke. 1987. Compilation of tRNA sequences and sequences of tRNA genes. Nucleic Acids Res. 15: r53-r188.

Suggs, S.V., T. Hirose, T. Miyake, E.H. Kawashima, M.J. Johnson, K. Itakura, and R.B. Wallace. 1981. Use of synthetic oligodeoxyribonucleotides for the isolation of specific cloned DNA sequences. In ICN-UCLA symposium on developmental biology using purified genes. (ed. D.D. Brown and D.F. Fox), pp. 683-693. Academic Press, New York.

Wakefield, L. and J.B. Gurdon. 1983. Cytoplasmic regulation of 5S RNA genes in nuclear-transplant embryos. EMBO $J$. 2: 1613-1619.

Wolffe, A.P. and D.D. Brown. 1988. Developmental regulation of two 5S ribosomal RNA genes. Science 241: 1626-1632.

Wormington, W.M. and D.D. Brown. 1983. Onset of 5S RNA gene regulation during Xenopus embryogenesis. Dev. Biol. 99: $248-257$. 


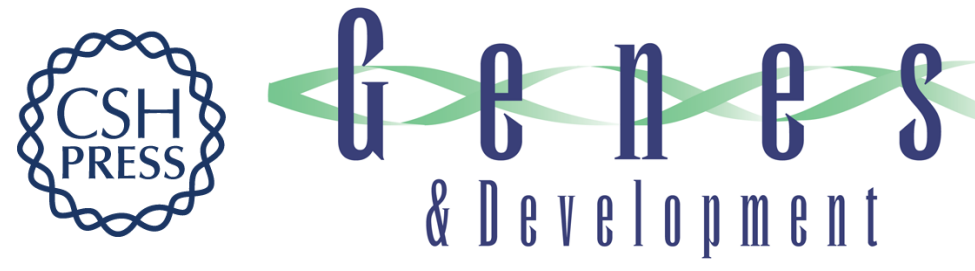

\section{Oocyte and somatic tyrosine tRNA genes in Xenopus laevis.}

F Stutz, E Gouilloud and S G Clarkson

Genes Dev. 1989, 3:

Access the most recent version at doi:10.1101/gad.3.8.1190

References This article cites 24 articles, 6 of which can be accessed free at:

http://genesdev.cshlp.org/content/3/8/1190.full.html\#ref-list-1

License

Email Alerting Receive free email alerts when new articles cite this article - sign up in the box at the top Service right corner of the article or click here.

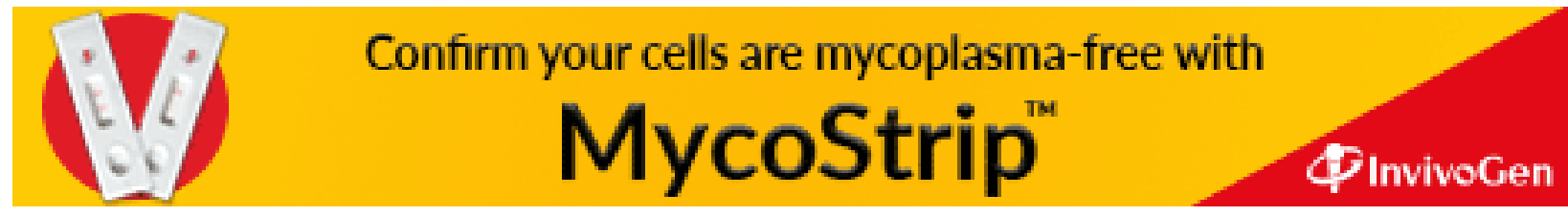

